\title{
Inversion polymorphism and extra bristles in Indian natural populations of Drosophila ananassae: joint variation
}

\author{
APARUP DAS*, SUJATA MOHANTY $\dagger \&$ B. B. PARIDA \\ Genetics Laboratory, Department of Zoology, Utkal University, Bhubaneswar-751 004, India
}

\begin{abstract}
Five Indian natural populations of Drosophila ananassae were analysed for chromosome inversions and the presence of individuals with extra scutellar bristles in the $F_{1}$ progeny of isofemale lines initiated from naturally impregnated females. Three commonly occurring inversions were found in these populations with varying frequencies as was the number of individuals with extra bristles (e.b.). Female individuals were more often found to carry extra scutellar bristles than were males. This result reveals that polygenic loci responsible for the determination of e.b. are widespread in Indian natural populations of $D$. ananassae. A significant positive correlation between the inversion frequency and the number of individuals with e.b. was detected in the isofemale lines of all the five populations. The $2 \mathrm{~L}$ inversion, alpha, was found to be closely associated with individuals with the e.b. phenotype. The observed results are compared with earlier results obtained for $D$. melanogaster. The association of the alpha inversion with the e.b. phenotype is discussed in relation to chromosomal evolution in the melanogaster species group.
\end{abstract}

Keywords: Drosophila ananassae, extra scutellar bristles, inversion polymorphism, sex difference.

\section{Introduction}

Inversion polymorphism is clearly a part of the adaptive machinery in natural populations of Drosophila. Several species of Drosophila have been screened worldwide for this phenomenon and different situations have been found to exist. In India, two cosmopolitan species of Drosophila, D. melanogaster and $D$. ananassae, have been widely investigated for chromosome inversion polymorphism (Das, 1994 for a review). Although a considerable amount of genotypic variation is generally detected in natural populations, few differences in phenotypic characters are usually observed. It has been suggested that the genetic basis of phenotypic changes is fundamental for understanding the mechanism of evolution in natural and experimental populations (Lande, 1983) and the study of quantitative characters in wild populations could prove to be interesting for evolutionary studies (David et al., 1977).

*Correspondence.

$\dagger$ Present address: Department of Life Science, Regional College of Education (NCERT), Bhubaneswar-751 007, India.
In $D$. melanogaster, it has been found that the scutellar phenotype is strongly canalized at four macrochaetae (bristles) and that the canalization is regulated by the scute locus (Rendel et al., 1965). Also, it has been determined that the normal number of four scutellar bristles in $D$. melanogaster is often so tightly controlled developmentally that a change in visible phenotype occurs only after a considerable amount of gene substitution (Rendel et al., 1965; Das \& Singh, 1992). It also has been estimated that to alter the chaeta number from four to three or five takes about eight times as many genetic changes as to alter the number from three to one (Lee \& Parsons, 1968). In natural populations of this species genetic variation for extra scutellar bristle phenotypes has been reported in India (Singh \& Das, 1991), Spain (Garcia-Vazquez et al., 1989) and Austria (Izquierdo et al., 1991). In all these studies, chromosome inversions, especially $\operatorname{In}(3 \mathrm{R}) \mathrm{C}$, are found to be positively correlated with the extra bristle phenotypes.

Drosophila ananassae is a cosmopolitan and domestic species which occurs throughout the tropical regions of the world and is found in abundance in the Indian subcontinent. Studies on the population genetics of 
chromosome inversion polymorphism have been undertaken extensively (Singh, 1988 for a review) but less attention has been given to morphometric characters. In this paper, we examine the correlation of two genetic variables (inversions and extra bristles (e.b.)) in isofemale lines of this species in five natural populations collected in ecologically different localities in India.

\section{Materials and methods}

Drosophila ananassae flies analysed during the present study come from five different localities in the east coastal region of India: Bhubaneswar (Orissa), Cuttack (Orissa), Ratnagiri (Orissa), Balasore (Orissa) and Howrah (West Bengal). From each place, flies were collected by exposing fermented banana baits in domestic and semidomestic areas. Each wild-caught female was individually placed in a fresh food vial to initiate one isofemale line. From each line, the salivary glands of one $F_{1}$ third instar larva were dissected out and stained in lacto-aceto-orcein for polytene chromosome preparation. The breakpoints of the inversions were determined following the standard polytene chromosome map of $D$. ananassae constructed by RayChaudhuri \& Jha (1966). Usually, four bristles are present in the scutellum and any additional bristle in this region would be counted as extra. Twenty individuals of each sex were scored in each line for the presence of extra scutellar bristles. For statistical analysis, the percentage data were transformed by arcsine transformation (Snedecor \& Cochran, 1967).

\section{Results}

Chromosomal analysis revealed the presence of three cosmopolitan inversions identified as alpha in $2 \mathrm{~L}$, delta in $3 \mathrm{~L}$ and eta in $3 \mathrm{R}$ (Fig. 1). The frequencies of these inversions in all five populations are shown in Table 1. It is evident that the frequency of these inversions varies among populations, delta being the most frequent (47.18 per cent) in Ratnagiri and the least frequent (24.19 per cent) in Howrah. Based on the frequency of flies with extra bristles, the isofemale lines were classified for each sex in all five populations. The data are presented in Table 2.

Almost all lines were found to have individuals of either sex with e.b., except some Cuttack lines where not a single individual of either sex was found to carry extra bristles ( 23 of 59 lines). No more than 10 per cent of flies of e.b. phenotype were detected in any isofemale line for either sex. Generally, lines with $0-5$ per cent of flies with e.b. were found to be more frequent than those with 5-10 per cent. Furthermore, more

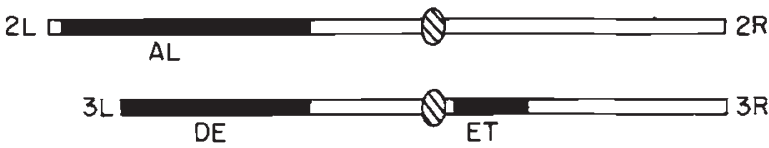

Fig. 1 The autosomes of Drosophila ananassae showing the locations of the alpha (AL), delta (DE) and eta (ET) inversions in $2 \mathrm{~L}, 3 \mathrm{~L}$ and $3 \mathrm{R}$, respectively.

Table 1 Frequencies (percentages) of three common inversions in Indian natural populations of Drosophila ananassae

\begin{tabular}{lcccc}
\hline & & \multicolumn{3}{c}{ Inversions (\%) } \\
\cline { 3 - 6 } Potal no. of & $\begin{array}{c}\text { Total } \\
\text { chromosome } \\
\text { analysed }\end{array}$ & $\begin{array}{c}\text { Alpha } \\
(2 \mathrm{~L})\end{array}$ & $\begin{array}{c}\text { Delta } \\
(3 \mathrm{~L})\end{array}$ & $\begin{array}{c}\text { Eta } \\
(3 \mathrm{R})\end{array}$ \\
\hline Bhubaneswar & 104 & 38.46 & 37.50 & 38.46 \\
Cuttack & 118 & 25.42 & 29.66 & 36.44 \\
Ratnagiri & 142 & 25.36 & 47.18 & 35.92 \\
Balasore & 66 & 34.84 & 28.79 & 39.39 \\
Howrah & 62 & 30.64 & 24.19 & 32.26 \\
\hline
\end{tabular}

lines were found to have females with e.b. (Table 2). All the data were pooled and the distributions of isofemale lines in four categories are given in Table 3 which clearly indicates that the majority of lines have both females and males with e.b. Interestingly, in some lines, individuals of only one sex bearing e.b. were detected, and the lines with only females with e.b. were more frequent than the lines having only males with e.b.

In order to study the relationship between the inversion frequency and the frequency of flies with extra bristles in isofemale lines, the correlation coefficient $(r)$ between these variables was calculated for each population (Table 4). For this computation, the frequencies of all three inversions were summed and the frequencies of e.b. in both sexes were combined in each line. In each population the two variables were found to be positively and significantly correlated (Table 4). This finding clearly indicates that inversions have a positive influence on the occurrence of individuals with e.b. On testing for independence, the alpha inversion was found to be more closely associated with the occurrence of e.b. individuals of both sexes in the populations (Table 5). Interestingly, in all populations, the majority of the lines were found to have both the alpha inversion and individuals with extra bristles and not a single line was detected in any of the populations as having the alpha inversion without e.b. A $2 \times 2$ contingency $\chi^{2}$ test was carried out in all the populations independently and the values show significant results in all populations except Balasore (Table 5). 
Table 2 Frequencies (percentages) of isofemale lines classified on the basis of the scutellar phenotype in both sexes of different natural populations of Drosophila ananassae

\begin{tabular}{|c|c|c|c|c|c|c|c|}
\hline \multirow[b]{3}{*}{ Population } & \multirow{3}{*}{$\begin{array}{c}\text { No. of } \\
\text { isofemale } \\
\text { lines }\end{array}$} & \multicolumn{6}{|c|}{ Isofemale lines $(\%)$} \\
\hline & & \multicolumn{3}{|c|}{ Males } & \multicolumn{3}{|c|}{ Females } \\
\hline & & I & II & III & I & II & III \\
\hline Bhubaneswar & 52 & 51.92 & 34.62 & 13.46 & 25.00 & 42.31 & 32.69 \\
\hline Cuttack & 59 & 77.79 & 11.86 & 10.17 & 61.62 & 20.34 & 18.64 \\
\hline Ratnagiri & 71 & 56.34 & 29.58 & 14.08 & 28.17 & 53.52 & 18.31 \\
\hline Balasore & 33 & 45.46 & 33.33 & 21.21 & 30.30 & 39.40 & 30.30 \\
\hline Howrah & 31 & 41.94 & 32.26 & 25.80 & 25.81 & 41.93 & 32.26 \\
\hline
\end{tabular}

I, no flies with extra bristhes; II, 0-5 per cent of flies with extra bristles; III, 5-10 per cent of flies with extra bristles.

Table 3 Distribution of isofemale lines with extra bristles in different natural populations of $D$. ananassae

\begin{tabular}{|c|c|c|c|c|c|}
\hline \multirow[b]{2}{*}{ Population } & \multirow[b]{2}{*}{$\begin{array}{c}\text { Total no. } \\
\text { of isofemale } \\
\text { lines }\end{array}$} & \multicolumn{4}{|c|}{ Distribution of lines with e.b. } \\
\hline & & $\begin{array}{c}\text { In neither } \\
\text { sex }\end{array}$ & $\begin{array}{c}\text { In both } \\
\text { sexes }\end{array}$ & $\begin{array}{c}\text { In } \\
\text { males } \\
\text { only }\end{array}$ & $\begin{array}{c}\text { In } \\
\text { females } \\
\text { only }\end{array}$ \\
\hline Bhubaneswar & 52 & 0 & 35 & 7 & 10 \\
\hline Cuttack & 59 & 23 & 21 & 7 & 8 \\
\hline Ratnagiri & 71 & 0 & 59 & 6 & 6 \\
\hline Balasore & 33 & 0 & 27 & 2 & 4 \\
\hline Howrah & 31 & 0 & 28 & 0 & 3 \\
\hline
\end{tabular}

Table 4 Correlation coefficients $(r)$ between inversion frequencies (all three inversions combined) and the frequencies of flies with extra bristles (data of both sexes combined) in isofemale lines of different natural populations of $D$. ananassae

\begin{tabular}{lccc}
\hline Population & $r$ & d.f. & Probability \\
\hline Bhubaneswar & +0.86 & 50 & $<0.001$ \\
Cuttack & +0.90 & 57 & $<0.001$ \\
Ratnagiri & +0.34 & 69 & $<0.01$ \\
Balasore & +0.42 & 31 & $<0.02$ \\
Howrah & +0.47 & 29 & $<0.01$ \\
\hline
\end{tabular}

Thus, the results clearly indicate that the alpha inversion and the occurrence of individuals with e.b. are positively related in natural populations of $D$. ananassae.

\section{Discussion}

It has been observed in $D$. melanogaster that the number of macrochaetae (bristles) is canalized (having little or no phenotypic effect) in natural populations and only in experimental conditions could significant changes in bristle number be seen (Singh \& Das, 1991; Das \& Singh, 1992). It has also been suggested that the phenotypic effect appears only when the threshold of expression that is fixed by the canalization is exceeded (Rendel, 1976; Ghysen \& Richelle, 1979). The results obtained in the present study, the first of their kind for $D$. ananassae, clearly indicate that there is considerable intra- and interpopulational variation in the frequencies of three common inversions and the number of individuals carrying extra scutellar bristles. However, only a low proportion of flies of either sex $(<10$ per cent) was found to have e.b. in the scutellar region and above all the majority of lines had $<5$ per 
Table 5 Association of isofemale lines with respect to the occurrence of the alpha inversion and extra bristles in different isofemale lines of $D$. ananassae

\begin{tabular}{|c|c|c|c|c|c|c|c|c|c|}
\hline \multirow[b]{2}{*}{ Population } & & & \multicolumn{4}{|c|}{ Association of isofemale lines } & \multirow[b]{2}{*}{$\chi^{2 *}$} & \multirow[b]{2}{*}{ d.f. } & \multirow[b]{2}{*}{ Probability } \\
\hline & \multicolumn{2}{|c|}{$\begin{array}{l}\text { Total no. of } \\
\text { isofemale lines }\end{array}$} & $\begin{array}{l}\text { With alpha, } \\
\text { with e.b. }\end{array}$ & $\begin{array}{l}\text { Without alpha, } \\
\text { with e.b. }\end{array}$ & $\begin{array}{l}\text { With alpha, } \\
\text { without e.b. }\end{array}$ & $\begin{array}{l}\text { Without alpha, } \\
\text { without e.b. }\end{array}$ & & & \\
\hline \multirow[t]{2}{*}{ Bhubaneswar } & 52 & Obs. & 40 & 8 & 0 & 4 & 10.13 & 1 & $<0.005$ \\
\hline & & Exp. & 36.92 & 11.08 & 3.08 & 0.94 & & & \\
\hline \multirow[t]{2}{*}{ Cuttack } & 59 & Obs. & 30 & 4 & 0 & 25 & 41.42 & 1 & $<0.001$ \\
\hline & & Exp. & 17.30 & 16.70 & 12.70 & 12.30 & & & \\
\hline \multirow[t]{2}{*}{ Ragnagiri } & 71 & Obs. & 36 & 25 & 0 & 10 & 9.73 & 1 & $<0.005$ \\
\hline & & Exp. & 30.93 & 30.07 & 5.07 & 4.93 & & & \\
\hline \multirow[t]{2}{*}{ Balasore } & 33 & Obs. & 23 & 8 & 0 & 2 & 2.01 & 1 & $>0.10$ \\
\hline & & Exp. & 21.61 & 9.39 & 1.39 & 0.61 & & & \\
\hline \multirow{2}{*}{ Howrah } & 31 & Obs. & 19 & 8 & 0 & 4 & 4.61 & 1 & $<0.05$ \\
\hline & & Exp. & 16.55 & 10.45 & 2.45 & 1.55 & & & \\
\hline
\end{tabular}

*After Yates' correction.

cent of flies of the decanalized phenotype with respect to e.b. Thus it can be concluded that polygenes determining e.b. variation are widespread in Indian populations of $D$. ananassae and that phenotypic variation in natural populations of this species has a genetic basis. Similar conclusions have been drawn for Indian $D$. melanogaster both in natural samples (Singh \& Das, 1991) and in selection experiments (Das \& Singh, 1992).

It seems from the results that the appearance of e.b. in one sex is inversely proportional to its occurrence in the other sex, at least in natural populations of this species. In this initial stage it is difficult to discuss the cause, but certainly this situation deserves further analysis. Although more females were detected with extra dorsocentral and scutellar bristles in several natural populations of Indian D. malanogaster (Singh \& Das, 1991), such a great difference has not been observed before.

Most importantly, inversion frequency was also found to be positively correlated with the frequency of individuals with extra scutellar bristles in $D$. ananassae. Besides detailed studies on D. melanogaster for such an association in different populations worldwide (GarciaVazquez et al., 1989; Singh \& Das, 1991; Izquierdo et al., 1991) and similar findings in selection experiments (Garcia-Vazquez \& Sanchez-Refusta, 1989; Das \& Singh, 1992), this is the first report of such an association in another cosmopolitan species of Drosophila. In D. melanogaster it has been found that significant genetic activity affecting chaeta number is present in all the major chromosomes (Mather, 1941) and polygenes determining e.b. were detected in all the three major chromosomes (Sheldon \& Milton, 1972). Also, Whittle (1969) found an influence of chromosome 3 on the increase in number of extra scutellar bristles, later supported by the localization of polygenes for e.b. on chromosome 3 (Rubio \& Albornoz, 1982). Unfortunately, we do not know whether such situations exist or such mechanisms occur in $D$. ananassae. Although much information on the genetics and biology of this species is now available (for details, see Tobari, 1993), our ignorance of the detailed genetics of this species prevents us from drawing any conclusions at this stage. More investigations are needed to solve this problem.

Our knowledge of chromosomal evolution in the melanogaster species group from the primitive karyotype to the ananassae subgroup (Dobzhansky, 1970) offers the opportunity to discuss an important aspect of the observed results - the close positive association of the alpha inversion and individuals with e.b. Since the third chromosome has been identified as influencing the e.b. character in D. melanogaster and the second chromosome of D.. ananassae is derived from the third chromosome of $D$. melanogaster, the conserved polygenic sequences are thought to be maintained during the whole course of chromosomal evolution in the melanogaster species group. Thus it could be assumed that the alpha inversion acts as a complex of polygenes, including factors that favour the expression of e.b. as described for the inversion In (3R) C in D. melanogaster (Garcia-Vazquez et al., 1989; Singh \& Das, 1991; Izquierdo et al., 1991). It might be true that the polygenes within the alpha inversion are in tight linkage with the inversion locus itself resulting in the observed close association between these two variables. How- 
ever, a detailed study involving directional selection experiments for the e.b. character and simultaneous observations of the behaviour of the alpha inversion will provide definite conclusions. This work is currently in progress in our laboratory.

\section{Acknowledgements}

The work was supported financially by the CSIR New Delhi in the form of a Research Associateship to the senior author. S.M. gratefuly acknowledges the NCERT (New Delhi) and the Principal, RCE Bhubaneswar, for encouragement and use of facilities. The authors thank the anonymous reviewer for valuable suggestions and critical comments on the original draft of the manuscript.

\section{References}

DAS, A. 1994. Chromosomal polymorphism in two cosmopolitan Drosophila species in India. (Submitted.)

DAS, A. AND SINGH, B. N. 1992. Selection for increased phenotypes of extra bristles in Drosophila melanogaster: correlated response in the frequency of In (3R)C inversion. Evol. Biol., 6, 15-38.

DAVID, J. R., BOCQUET, C. AND DE SCREEMAEKER LOUIS, M. 1977. Genetic latitudinal adaptation of Drosophila melanogaster: new discriminative biometrical traits between European and equatorial African populations. Genet. Res., 30 , 247-255.

DOBZHANSKy, Th. 1970. Genetics of The Evolutionary Process. Columbia University Press, New York.

GARCIA-VAZQUEZ, E. AND SANCHEZ-REFUSTA, F. 1989. Chromosomal polymorphism and extra bristles of Drosophila melanogaster: joint variation under selection in isofemale lines. Genetica, 79, 91-96.

GARCIA-VAZQUEZ, E., SANCHEZ-REFUSTA, F. AND RUBIO, J. 1989. Chromosome inversions and frequency of extra bristles in natural populations of Drosophila melanogaster. J. Hered., 80, 193-196.
GHYSEN, A. AND RICHELLE, J. 1979. Determination of sensory bristles and pattern formation in Drosophila. II. The achaete-scute locus. Devel. Biol., 70, 438-452.

IZQUIERDO, J. I., GARCIA-VAZQUEZ, E. AND VILLAR, B. 1991. Correlated variation of chromosomal inversion (3R)C and extra bristles in Drosophila melanogster. Heredity, 67, 183-187.

LANDE, R. 1983. The response to selection on major and minor mutations affecting a metrical trait. Heredity $\mathbf{5 0}$ 47-65.

LEE, B. T. O. AND PARSONS, P. A. 1968. Selection, prediction and response. Biol. Rev., 43, 139-174.

MATHER, K. 1941. Variation and selection of polygenic characters. J. Genet., 41, 159-193.

RENDEL, J. M. 1976. Is there a gene regulating the scute locus on the third chromosome of Drosophila melanogaster? Genetics, 83, 573-600.

RENDEL, J. M., SHELDON, B. L. AND FINLAY, D. 1965. Canalization of development of scutellar bristles of Drosophila by control of the scute locus. Genetics, 52, 1137-1151.

RAY-CHAUDHURI, S. P. AND JHA, A. R. 1966. Studies on salivary gland chromosomes of Indian Drosophila ananassae. Proc. Int. Cell Biol. Meeting, Bombay, pp. 352-383.

RUBio, J. AND ALBORNOZ, J. 1982. Supresion y adicion de macroquetas dorsocentrales y escutelares en Drosophila melanogaster. Rev. Real A.C. Cien Ex. Fis. y Nat., 76, 775-802.

SHELDON, B. L. AND MILTON, N. K. 1972. Studies on the scutellar bristles of Drosophila melanogaster. II. Long term selection for high bristle number in the Oregon RC strain and correlated response in abdominal chaetae. Genetics, 71, $567-595$.

SINGH, B. N. 1988. Chromosomal polymorphism in Drosophila ananassae. Indian Rev. Life Sci., 8, 147-168.

SINGH, B. N. AND DAS, A. 1991. Association of inversion polymorphism and frequency of extra bristles in Indian natural populations of Drosophila melanogaster. Evol. Biol., 5, $185-200$

SNEDECOR, G. W. AND COCHRAN, w. G. 1967. Statistical Methods, 6th edn. Iowa State University Press, Ames, Iowa.

TOBARI, y. N. (ed.) 1993. Drosophila ananassae: Genetical and Biological Aspects. Japan Scientific Societies Press, Tokyo.

WHITTLE, J. R. S. 1969. Genetic analysis of the control of number and pattern of scetullar bristles in Drosophila melanogaster. Genetics, 63, 167-181. 